\title{
Pancreaticoduodenectomy: Impact of Volume on Outcomes at a Tertiary Care Center. Our Experience in Single Institute of Nepal.
}

Sunit Agrawal ( $\square$ sunit.aga@gmail.com )

B.P. Koirala Institute of Health Sciences https://orcid.org/0000-0003-4171-9321

Bhawani Khanal

BP Koirala Institute of Health Sciences

Ujjwal Das

BP Koirala Institute of Health Sciences

Suresh Prasad Sah

BP Koirala Institute of Health Sciences

Rakesh Kumar Gupta

BP Koirala Institute of Health Sciences

\section{Research Article}

Keywords: Pancreaticoduodenectomy, Postoperative outcome, Whipples operation

Posted Date: July 6th, 2021

DOI: https://doi.org/10.21203/rs.3.rs-658424/v1

License: (1) (1) This work is licensed under a Creative Commons Attribution 4.0 International License.

Read Full License 


\section{Abstract}

\section{Background}

Pancreaticoduodenectomy is a complex high risk surgical procedure usually done for malignant disease carrying significant postoperative morbidity and mortality. An audit and analysis of rate of postoperative morbidity and mortality and the impact of case volume can provide information about the lacunas in patient care and methods to improve it for safe and early discharge of patients. This study was conducted to find out demographic profile, the rate of perioperative morbidities, mortality and impact of case volume on patients undergoing pancreaticoduodenectomy for malignant disease which may serve as a guide to uplift the patient care in our center.

Methods

Retrospective analysis of prospectively collected data of patients undergoing pancreaticoduodenectomy from 2015 to 2019 was performed. A total of 62 patients were included in the study. Patients clinicdemographic details, intraoperative and postoperative events were recorded. Rate of various postoperative morbidities and mortality and year wise trend of these factors were analyzed.

Results

Most of the patients were in sixth decade of life (38.7\%) with male preponderance (61.3\%). Pancreatic cancer was most commonly seen followed by cholangiocarcinoma (46.8\%).

SSI (32.3\%), intraabdominal collection (25.8\%), anastomotic leak (14.5\%), pancreatic fistula (22.6\%), postpancreatectomy hemorrhage $(8.1 \%)$ were the major postoperative events. Mortality was found in $12.9 \%$ patients.

\section{Conclusion}

There has been a decrease in rate of all these postoperative adverse events and improvement in the intraoperative blood loss and surgical duration with advancing years and increasing number of cases.

\section{Introduction}

Pancreatic cancer remains one of the cancers with the poorest prognosis, with an overall 5-year survival rate of about $5 \%$, without much difference between high-income countries and low-income and middleincome countries [1]. Pancreaticoduodenectomy (PD) is a complex, high-risk surgical procedure usually performed for malignancy of the pancreatic head or periampullary region[2].

For the first time, Allen O Whipple described pancreaticoduodenectomy in 1935 when he modified the procedure that was performed before by Alessandro Codivilla in Italy and Walter Keusch in Germany [3]. The prevalence of this disease increases with age in the population. Patients aged 20-29 years old have an annual incidence of 0.1 cases of pancreatic cancer per 100,000 population, while patients older than 
80 have an annual incidence of 87.2 cases per 100,000 population. The causes of pancreatic cancer are unknown, but we consider risk factors like smoking and tobacco usage, alcohol and coffee consumption, history of diabetes, or chronic pancreatitis [4]. At the time of diagnosis, only $20 \%$ of patients are a candidate for pancreaticoduodenectomy. Even after a successful pancreatic resection, the prognosis is very poor with a 5-year survival of approximately $4-30 \%$ and a median survival of $18-29$ months [5].

This procedure is associated with significant postoperative morbidity, rates of which range from $30 \%$ to $60 \%$. Major postoperative complications include: pancreatic leak or fistula, intra-abdominal abscess, bile leak, postoperative hemorrhage requiring blood transfusion or re-exploration, delayed gastric emptying, and complications related to the surgical site such as infection and wound dehiscence [6]. Various studies have demonstrated that high volume tertiary centers have significantly lower $(<5 \%)$ in-hospital mortality rates for pancreaticoduodenectomy than the low volume centers $(>10 \%)$ [2]. We set out to conduct this systematic research to link our evidence regarding the volume of cases and outcome at tertiary care center in underdeveloped country and to implement the data to improvise our practice in managing such patients, and analyze the impact of turning our department from a medium to a high volume care provider of PD.

\section{Materials And Methods}

Patients who underwent pancreaticoduodenectomy for malignancy in our institute in the past 5 years (2015-2019) were included in our study. Patients who underwent pancreaticoduodenectomy for benign and trauma cases were excluded. 62 patients who fulfilled inclusion criteria were retrospectively analysed in our study.

\section{Study procedure:}

Data were collected retrospectively from a prospectively maintained database in the medical record of our institue who underwent pancreaticoduodenectomy for periampullary carcinoma and pancreatic cancer. Patients' demographic details, symptoms, baseline preoperative parameters, surgical parameters, intraoperative and postoperative events were recorded and analyzed. All the surgical procedures were performed by a senior surgeon with his team. The rate of complication was recorded and year wise trend of various intraoperative parameters as well as postoperative adverse events was recorded and analyzed.

\section{STATISTICAL ANALYSIS:}

All statistical analysis was done using SPSS version 19. Continuous variables like age, blood investigation, blood loss and duration of stay were presented as means and standard deviation for all normally distributed variables. Descriptive variables were analyzed and recorded as frequency.

\section{Results}


This study includes a total of 62 patients who underwent pancreaticoduodenectomy for malignant disease from 2015 to 2019 in accordance with the inclusion and exclusion criteria.

Table 1 shows basic demographic details and symptoms of the patients at presentation. In this study, age of the study population ranged from 33years to 89 years with mean age of $58.56 \pm 12.54$ years. Amongst a total of 62 patients, $61.3 \%$ were male and $38.7 \%$ were female. $30.6 \%$ of the population was found to be smokers. Diabetes and hypertension were seen in $17.7 \%$ and $6.5 \%$ of patients respectively while comorbidity was absent in the remaining $75.8 \%$. Of the total 62 patients, jaundice was the most common symptom (80.7\%), pain abdomen was present in $38.7 \%$, clay-colored stool in $41.9 \%$, weight loss in $67.7 \%$, pruritus in $61.3 \%$ and upper gastrointestinal bleed was observed in $6.5 \%$ of patients. The mean duration of hospital stay was $15.35 \pm 8.91$ days.

Table 3 demonstrates the baseline preoperative parameters of study participants. The mean hemoglobin is $10.27 \pm 1.83 \mathrm{~g} / \mathrm{dL}$, total count is $12550 \pm 5616.94$ cells $/ \mathrm{mm}^{3}$, platelet count is $318500 \pm 135946.43$ cells $/ \mathrm{mm}^{3}$, PT is $18.41 \pm 3.19 \mathrm{sec}$ and INR is $1.38 \pm 0.26$. Similarly, the mean total protein of the study participants is $5.36 \pm 1.35 \mathrm{~g} / \mathrm{dL}$, serum albumin is $2.73 \pm 0.66 \mathrm{~g} / \mathrm{dL}$, total serum bilirubin is $6.979 \pm 4.19$ $\mathrm{mg} / \mathrm{dL}$, direct bilirubin is $4.86 \pm 3.53 \mathrm{mg} / \mathrm{dL}$, ALP is $461.45 \pm 291.61$ (IU/L), urea is $21.72 \pm 14.56 \mathrm{mg} / \mathrm{dL}$, creatinine is $0.597 \pm 0.32 \mathrm{mg} / \mathrm{dL}$ and CA $19-9$ is $33.72 \pm 66.96 \mathrm{U} / \mathrm{mL}$. The mean intraoperative blood loss was $321.77 \pm 105.43 \mathrm{~mL}$ and the mean operative duration was $5.23 \pm 0.87$ hours.

Table 4 demonstrates the overall rate of all the postoperative morbidities with around one-third of the study population (29\%) with no any complications. Postoperative pancreatic fistula in $22.6 \%$ of patients, surgical site infection in $32.3 \%$ of patients, chest infection in $38.7 \%$ of patients, post-pancreatectomy hemorrhage in $8.1 \%$ of patients, anastomotic leak in $14.5 \%$ study participants, intra-abdominal collection in $25.8 \%$ participants, and acute kidney injury in $12.9 \%$ patients. Similarly, $17.7 \%$ of patients underwent reintubation, and $25.8 \%$ patients underwent readmission. Total mortality observed was $12.9 \%$.

Table 5 illustrates the year-wise trend of various postoperative adverse events of the study participants. A total of 9 patients underwent pancreaticoduodenectomy in the year 2015 of which every patient developed one or more of the complications like two patients developed an anastomotic leak, 4 patients suffered from surgical site infection, 4 patients suffered from a chest infection, one patient developed post-pancreatectomy hemorrhage, 5 patients developed postoperative pancreatic fistula, 5 patients developed intraabdominal collection, 2 patients developed acute kidney injury, 2 patients underwent reintubation, and 5 patients underwent readmission. Two patients died in 2015.

Similarly, a total of 11 patients underwent pancreaticoduodenectomy in the year 2016 amongst which two patients developed an anastomotic leak, 7 patients suffered from surgical site infection, 7 patients developed chest infection, 2 patients had post-pancreatectomy hemorrhage, 3 patients developed postoperative pancreatic fistula, 4 patients developed intraabdominal collection, 2 patients developed acute kidney injury, 4 patients underwent re-intubation, and 4 patients underwent readmission. Three patients died in 2016. 
Similarly, a total of 12 patients underwent pancreaticoduodenectomy in the year 2017 of which 3 patients did not develop any complications, 3 patients developed an anastomotic leak, 3 patients suffered from surgical site infection, 5 patients suffered from a chest infection, one patient developed postpancreatectomy hemorrhage, 3 patients developed postoperative pancreatic fistula, 3 patients developed intraabdominal collection, 1 patient developed acute kidney injury, 2 patients underwent re-intubation, and 3 patients underwent readmission. One patient died in 2017.

A total of 15 patients underwent pancreaticoduodenectomy in the year 2018 of which 8 patients did not develop any complications, 1 patient developed an anastomotic leak, 2 patients suffered from surgical site infection, 4 patients suffered from a chest infection, 1 patient developed post-pancreatectomy hemorrhage, one patient developed postoperative pancreatic fistula, 2 patients developed intraabdominal collection, one patient developed acute kidney injury, 2 patients underwent re-intubation, and 2 patients underwent readmission. One patient died in 2018.

Likewise, a total of 15 patients underwent pancreaticoduodenectomy in the year 2019 of which 7 patients did not develop any complications, 1 patient developed an anastomotic leak, 4 patients suffered from surgical site infection, 4 patients suffered from a chest infection, no patient developed postpancreatectomy hemorrhage, 2 patients developed postoperative pancreatic fistula, 2 patients developed intraabdominal collection, 2 patients developed acute kidney injury, 1 patient underwent re-intubation, and 2 patients underwent readmission. One patient died in 2019.

Figures 2, 3, and 4 give a pictorial demonstration of the decreasing trend of various postoperative adverse events as a line diagram.

Table 6 shows the association of three parameters: blood loss during the surgery, duration of surgery and hospital stay in terms of mean and standard deviation with the yearly trend from 2015 to 2019. Though the mean difference between considered parameters is not statistically significant in respect to consequent years from 2015 to 2019, data do suggest 2015 as the year with the least favorable outcome with highest blood loss, duration of surgery and hospital stay.

\section{Table 1: Demographic profile and symptoms.}




\begin{tabular}{|ll|}
\hline Variables & Frequency (\%) \\
\hline Age (mean \pm SD) & $58.56 \pm 12.54$ years \\
\hline \multicolumn{1}{|c|}{ Male } & \\
Female & $61.3 \%$ \\
\hline Smoker & $38.7 \%$ \\
\hline Co-morbidities & $30.6 \%$ \\
\hline Diabetes & \\
Hypertension & $17.7 \%$ \\
CoPD & $6.5 \%$ \\
None & $0 \%$ \\
\hline Symptoms & $75.8 \%$ \\
Pain abdomen & \\
Jaundice & $38.7 \%$ \\
Clay coloured stool & $80.6 \%$ \\
Weight loss & $41.9 \%$ \\
Pruritus & $67.7 \%$ \\
UGl bleed & $61.3 \%$ \\
\hline Duration of hospital stay (mean \pm SD) & $6.5 \%$ \\
\hline
\end{tabular}

Table 2: Histopathological diagnosis of study participants.

\begin{tabular}{|ll|}
\hline \multicolumn{1}{|c|}{ Diagnosis } & Frequency (\%) \\
\hline Cholangiocarcinoma & $30.6 \%$ \\
\hline Pancreatic head cancer & $46.8 \%$ \\
\hline Ampullary & $16.1 \%$ \\
\hline Duodenal cancer & $6.5 \%$ \\
\hline
\end{tabular}

Table 3: Baseline laboratory parameters of study participants. 


\begin{tabular}{|ll|}
\hline Variables & Mean \pm SD \\
\hline Laboratory findings: & \\
Hemoglobin $(\mathrm{g} / \mathrm{dl})$ & $10.27 \pm 1.83$ \\
Total count ( cells/mm3) & $12250.00 \pm 5616.94$ \\
Platelets (cells/mm3) & $318500.00 \pm 135946.43$ \\
PT (seconds) & $18.41 \pm 3.19$ \\
INR & $1.38 \pm 0.26$ \\
Total protein (g/dl) & $5.36 \pm 1.35$ \\
Serum Albumin (g/dl) & $2.73 \pm 0.66$ \\
Serum bilirubin (mg/dl) & \\
\multicolumn{1}{|c|}{ Total } & $6.979 \pm 4.19$ \\
\multicolumn{1}{|c|}{ Direct } & $4.86 \pm 3.53$ \\
ALP (IU/L) & $461.45 \pm 291.61$ \\
RBS (mg/dl) & $120.43 \pm 52.32$ \\
Serum Urea (mg/dl) & $21.72 \pm 14.56$ \\
Serum Creatinine (mg/dl) & $0.597 \pm 0.32$ \\
CA 19-9 (U/ml) & $33.72 \pm 66.96$ \\
\hline Preoperative ERCP (\%) & $6.5 \%$ \\
\hline Intraoperative & $321.774 \pm 105.43 \mathrm{ml}$ \\
Blood loss: (Mean $\pm \mathrm{SD})$ & $5.23 \pm 0.87$ hours \\
Operative duration: (Mean $\pm \mathrm{SD})$ & \\
\hline
\end{tabular}

Table 4: Rate of postoperative adverse events in study participants. 


\begin{tabular}{|ll|}
\hline Complications $(\mathbf{n})$ & Frequency $(\%)$ \\
\hline No complications & $29.03 \%$ \\
\hline POPF & $22.6 \%$ \\
\hline SSI & $32.3 \%$ \\
\hline Chest infection & $38.7 \%$ \\
\hline PPH & $8.1 \%$ \\
\hline Anastomotic leak & $14.5 \%$ \\
\hline Intra-abdominal collection & $25.8 \%$ \\
\hline AKI & $12.9 \%$ \\
\hline Re-intubation & $17.7 \%$ \\
\hline Mortality & $12.9 \%$ \\
\hline Readmission & $25.8 \%$ \\
\hline
\end{tabular}

Table 5: Trend of postoperative outcomes from 2015-2019

\begin{tabular}{|llllll|}
\hline Complications $(n)$ & $\begin{array}{l}2015 \\
(n=9)\end{array}$ & $\begin{array}{l}2016 \\
(n=11)\end{array}$ & $\begin{array}{l}2017 \\
(n=12)\end{array}$ & $\begin{array}{l}2018 \\
(n=15)\end{array}$ & $\begin{array}{l}2019 \\
(n=15)\end{array}$ \\
\hline No complications $(n=18)$ & 0 & 0 & 3 & 8 & 7 \\
\hline Anastomotic leak $(n=9)$ & 2 & 2 & 3 & 1 & 1 \\
\hline SSI $(n=20)$ & 4 & 7 & 3 & 2 & 4 \\
\hline Chest infection $(n=24)$ & 4 & 7 & 5 & 4 & 4 \\
\hline PPH $(n=5)$ & 1 & 2 & 1 & 1 & 0 \\
\hline POPF $(n=14)$ & 5 & 3 & 3 & 1 & 2 \\
\hline Intra-abdominal collection $(n=16)$ & 5 & 4 & 3 & 2 & 2 \\
\hline AKI $(n=8)$ & 2 & 2 & 1 & 1 & 2 \\
\hline Re-intubation $(n=11)$ & 2 & 4 & 2 & 2 & 1 \\
\hline Mortality $(n=8)$ & 2 & 3 & 1 & 1 & 1 \\
\hline Readmission $(n=16)$ & 5 & 4 & 3 & 2 & 2 \\
\hline
\end{tabular}

Table 6: Association between different parameters and mean difference in the years from 2015 to 2019 


\begin{tabular}{|c|c|c|c|c|c|c|}
\hline Parameters & $2015($ Mean \pm SD $)$ & $\begin{array}{l}2016 \\
(\text { Mean } \pm S D)\end{array}$ & $\begin{array}{l}2017 \\
(\text { Mean } \pm S D)\end{array}$ & $\begin{array}{l}2018 \\
(\text { Mean } \pm S D)\end{array}$ & $\begin{array}{l}2019 \\
(\text { Mean } \pm \text { SD) }\end{array}$ & $\begin{array}{l}\mathrm{p} \text { - } \\
\text { value }\end{array}$ \\
\hline $\begin{array}{l}\text { Blood loss } \\
\text { (ml) }\end{array}$ & $344.4 \pm 186.2$ & $354.5 \pm 133.1$ & $295.8 \pm 72.2$ & $313.3 \pm 61.4$ & $313.3 \pm 78.9$ & 0.679 \\
\hline $\begin{array}{l}\text { Duration of } \\
\text { surgery } \\
\text { (Hours) }\end{array}$ & $5.8 \pm 1.2$ & $5.5 \pm 0.9$ & $4.8 \pm 0.7$ & $5.0 \pm 0.6$ & $5.2 \pm 0.7$ & 0.067 \\
\hline $\begin{array}{l}\text { Duration of } \\
\text { Hospital } \\
\text { Stay (Day) }\end{array}$ & $17.0 \pm 10.5$ & $15.3 \pm 9.2$ & $13.5 \pm 8.8$ & $14.8 \pm 7.9$ & $16.4 \pm 9.6$ & 0.909 \\
\hline
\end{tabular}

\section{Discussion}

Pancreaticoduodenectomy is a complex surgery that is done for various benign and malignant causes and it is associated with numerous intraoperative as well as postoperative difficulties and adverse events [7]. In this study, we set out to conduct a retrospective analysis of baseline characteristics and various postoperative adverse events in patients who underwent surgery for malignant disease in our center.

The incidence of periampullary carcinoma increases with age and most of the patients in our study were in their sixth decade of life which is similar to other previous studies [8]. Male preponderance for the malignant disease has been observed.

The majority of the study participants presented features of obstructive jaundice which is classical and consistent with all previous studies. Many of the patients (38.6\%) also presented with pain abdomen which may be attributable to cholangitis or associated pancreatitis (8). Pain abdomen may also arise because of the tumor itself or the infiltration of the tumor to the retroperitoneal nerves and nerves surrounding the pancreas [9]. Few patients (6.5\%) also presented with features of upper gastrointestinal bleeding in the form of hematemesis or malena. This may be due to coagulopathy caused by obstructive jaundice leading to decreased absorption of fat-soluble vitamins especially Vitamin $\mathrm{K}$ which is required for the formation of factors II, VII, IX, and X.

In our study, $17.7 \%$ patients presented with diabetes mellitus. This may be attributed to the presence of new-onset diabetes mellitus or chronic pancreatitis in patients with pancreatic cancer [9]. However, the majority of patients had no comorbidities at all. The majority of study participants were diagnosed to have pancreatic cancer (46.8\%) followed by cholangiocarcinoma (30.6\%) and ampullary cancer (16.1\%). Only a few patients had duodenal cancer (6.5\%).

Majority of the patients developed chest infection postoperatively ( $38.7 \%$ vs $28 \%$ ) which is higher in comparison to other studies [10]. The observed higher pulmonary complication may be due to the old age and poor pulmonary reserve of majority of patients who underwent surgery. Poor pain control due to lack of modern analgesic support such as patient-controlled analgesia in a resource-limited setup like ours 
and also, epidural analgesia is given only for 2-3 days postoperatively which may have caused a lack of adequate participation of patients for chest physiotherapy and incentive spirometry leading to chest infections. In a similar study conducted in a resource-limited setup by Karim et al, high rates of pulmonary complications were observed due to inadequate pain control and chest physiotherapy [6]. With regards to these causes, various steps were taken which has led to a static rate of chest infection in our setup and makes us hopeful to reduce it further.

Surgical site infection is a common complication following pancreaticoduodenectomy causing increased hospital stay [11], re-admission, and increased cost of treatment [12]. In our study, a majority of patients developed postoperative surgical site infection. This may be attributed to the poor nutritional status of the patient due to underlying malignant disease, intraoperative blood transfusion, preoperative biliary stenting which are known to cause an increased incidence of surgical site infection [13,14]. Precautions against these factors have led to a decreasing trend of surgical site infection in our institute.

The overall rate of postoperative pancreatic fistula (22\%) in our setup was found to be similar to other studies (10\% to $29 \%$ ) [15]. There is a decrease in the rates of pancreatic fistula following pancreaticoduodenectomy in our setup. This may be attributed to the improvement in surgical skill and technique of the operating surgeon with an increase in the volume of cases and experience.

Postpancreatectomy hemorrhage is one of the most dreaded complications following pancreaticoduodenectomy. It is associated with mortality as high as $30 \%$ with a decreasing trend after the introduction of minimally invasive procedures such as endoscopy and angiographic embolization. The rate of post-pancreatic hemorrhage is similar to other studies [16] and there has been a further decrease in the incidence of post-pancreatectomy hemorrhage.

Anastomotic leak following pancreaticoduodenectomy is another dreaded complication. The patient may develop a biliary leak and pancreatic leak leading to biliary peritonitis or pancreatic fistula. The rate of anastomotic leakage in our setup is similar to other studies [17]. There has been a decrease in the trend of anastomotic leakage with advancing years and number of cases; this may be attributed to the improved surgical technique and use of prophylactic octreotide postoperatively in our patients.

Almost all the cases have been admitted in ICU following pancreaticoduodenectomy in our setup. This is due to the unavailability of monitoring facilities and a trend of ICU admission following major surgeries for monitoring in our setup.

The rate of mortality following pancreaticoduodenectomy is similar to other studies in our setup in the past five years [18]. There has been a decrease in mortality in recent years with only single mortality in 2019. The various causes for mortality include post-pancreatectomy hemorrhage, intra-abdominal collection, sepsis, anastomotic leak, myocardial infarction, etc. The reduction in mortality is due to early recognition and prompt intervention with intensive care done in our setup following high-risk complications. 
There has been a significant reduction in hospital stay with advancing years in our hospital. The duration of hospital stay in our setup is similar to other studies [19]. The observed reduction in length of stay is due to increased operative skills, decreased rate of complication, early detection, and treatment of various complications, and decreased readmission rates as well.

The strength of our study is that we have an adequate sample size with respect to our scenario with adequate power of the study. This study highlights the improvement in perioperative outcome following pancreaticoduodenectomy with respect to various intraoperative factors such as duration of surgery, decreased blood loss, decreased incidence of various postoperative adverse events and reduced length of hospital stay and cost of treatment. This sheds light on the fact that with an increase in experience and number of cases in our hospital there is an improvement in the perioperative outcome of patients following pancreaticoduodenectomy in our hospital. This study may serve as a source of various changes that can be made to improve the outcomes in a limited setup like ours.

Pancreaticoduodenectomy is a complex surgery demanding meticulous surgical skills and good postoperative care for early detection and management of postoperative adverse events. There is an improvement of surgical skills which is evident by the decreased intraoperative blood loss and decreased duration of surgery in our setup. Also, the decreased rate of various postoperative adverse events in our study points to the fact that with an increase in volume and experience of pancreaticoduodenectomy, a picture of a better outcome with reduced morbidity and mortality can be expected in a resource-limited setup and we are not far behind the developed countries in this regard.

\section{Declarations}

Funding : Not applicable

Conflicts of interest/Competing interests : None decleared.

Availability of data and material : Hospital record section.

Code availability:Not applicable

\section{Authors' contributions}

Sunit Agrawal- Data collection, analysis, result and discussion.

Bhawani Khanal- Data collection and framing manuscript

Ujjwal Das- Data analysis, result asnd discussion

Suresh Prasad Sah- Data analysis and discussion

Rakesh Kumar Gupta- Discussion and proof reading 
Ethics approval : The ethical approval was obtained from the institutional review committee (IRC) of our institute. The reference number is IRC/1991/020.

Consent to participate: Not applicable

Consent for publication: Not applicable

\section{References}

1. GBD 2017 Pancreatic Cancer Collaborators. The global, regional, and national burden of pancreatic cancer and its attributable risk factors in 195 countries and territories, 1990-2017: a systematic analysis for the Global Burden of Disease Study 2017. Lancet Gastroenterol Hepatol. 2019 Dec;4(12):934-47.

2. Shah OJ, Singh M, Lattoo MR, Bangri SA. Pancreaticoduodenectomy: A study from India on the impact of evolution from a low to a high volume unit. World J Gastrointest Surg. 2016 Aug 27;8(8):5839.

3. Saraee A, Vahedian-Ardakani J, Saraee E, Pakzad R, Wadji MB. Whipple procedure: a review of a 7year clinical experience in a referral center for hepatobiliary and pancreas diseases. World J Surg Oncol. 2015 Mar 11;13:98.

4. Romano G, Agrusa A, Galia M, Di Buono G, Chianetta D, Sorce V, et al. Whipple's pancreaticoduodenectomy: Surgical technique and perioperative clinical outcomes in a single center. Int $J$ Surg Lond Engl. 2015 Sep;21 Suppl 1:S68-71.

5. van Dijk SM, Heerkens HD, Tseng DSJ, Intven M, Molenaar IQ, van Santvoort HC. Systematic review on the impact of pancreatoduodenectomy on quality of life in patients with pancreatic cancer. HPB. 2018 Mar;20(3):204-15.

6. Karim SAM, Abdulla KS, Abdulkarim QH, Rahim FH. The outcomes and complications of pancreaticoduodenectomy (Whipple procedure): Cross sectional study. Int J Surg Lond Engl. 2018 Apr;52:383-7.

7. Moossa AR. Reoperation for pancreatic cancer. Arch Surg Chic III 1960. 1979 Apr;114(4):502-4.

8. Patra DP, Basu A, De S, Vatsal S. Pancreaticoduodenectomy in a Government Medical CollegeShould We Proceed!!! Indian J Surg. 2010 Oct;72(5):381-5.

9. Wolfgang CL, Herman JM, Laheru DA, Klein AP, Erdek MA, Fishman EK, et al. Recent Progress in Pancreatic Cancer. CA Cancer J Clin. 2013 Sep;63(5):318-48.

10. Wiltberger G, Muhl B, Benzing C, Atanasov G, Hau H-M, Horn M, et al. Preoperative risk stratification for major complications following pancreaticoduodenectomy: Identification of high-risk patients. Int $\mathrm{J}$ 
Surg Lond Engl. 2016 Jul;31:33-9.

11. Nanashima A. Clinicopathological Parameters Associated with Surgical Site Infections in Patients who Underwent Pancreatic Resection. :22.

12. Kirkland KB, Briggs JP, Trivette SL, Wilkinson WE, Sexton DJ. The impact of surgical-site infections in the 1990s: attributable mortality, excess length of hospitalization, and extra costs. Infect Control Hosp Epidemiol. 1999 Nov;20(11):725-30.

13. Gavazzi F, Ridolfi C, Capretti G, Angiolini MR, Morelli P, Casari E, et al. Role of preoperative biliary stents, bile contamination and antibiotic prophylaxis in surgical site infections after pancreaticoduodenectomy. BMC Gastroenterol [Internet]. 2016 Mar 31 [cited 2021 Jun 13];16. Available from: https://www.ncbi.nlm.nih.gov/pmc/articles/PMC4815172/

14. Higgins RM, Helm MC, Kindel TL, Gould JC. Perioperative blood transfusion increases risk of surgical site infection after bariatric surgery. Surg Obes Relat Dis Off J Am Soc Bariatr Surg. 2019 Apr;15(4):582-7.

15. Bassi C, Butturini G, Molinari E, Mascetta G, Salvia R, Falconi M, et al. Pancreatic fistula rate after pancreatic resection. The importance of definitions. Dig Surg. 2004;21(1):54-9.

16. Kasumova GG, Eskander MF, Kent TS, Ng SC, Moser AJ, Ahmed M, et al. Hemorrhage after pancreaticoduodenectomy: does timing matter? HPB. 2016 Oct;18(10):861-9.

17. Adam U, Makowiec F, Riediger H, Benz S, Liebe S, Hopt UT. [Pancreatic leakage after pancreas resection. An analysis of 345 operated patients]. Chir Z Alle Geb Oper Medizen. 2002 May;73(5):466-73.

18. Narayanan S, Martin AN, Turrentine FE, Bauer TW, Adams RB, Zaydfudim VM. Mortality after pancreaticoduodenectomy: assessing early and late causes of patient death. J Surg Res. 2018 Nov;231:304-8.

19. Brooks AD, Marcus SG, Gradek C, Newman E, Shamamian $P$, Gouge $T H$, et al. Decreasing length of stay after pancreatoduodenectomy. Arch Surg Chic III 1960. 2000 Jul;135(7):823-30.

\section{Figures}




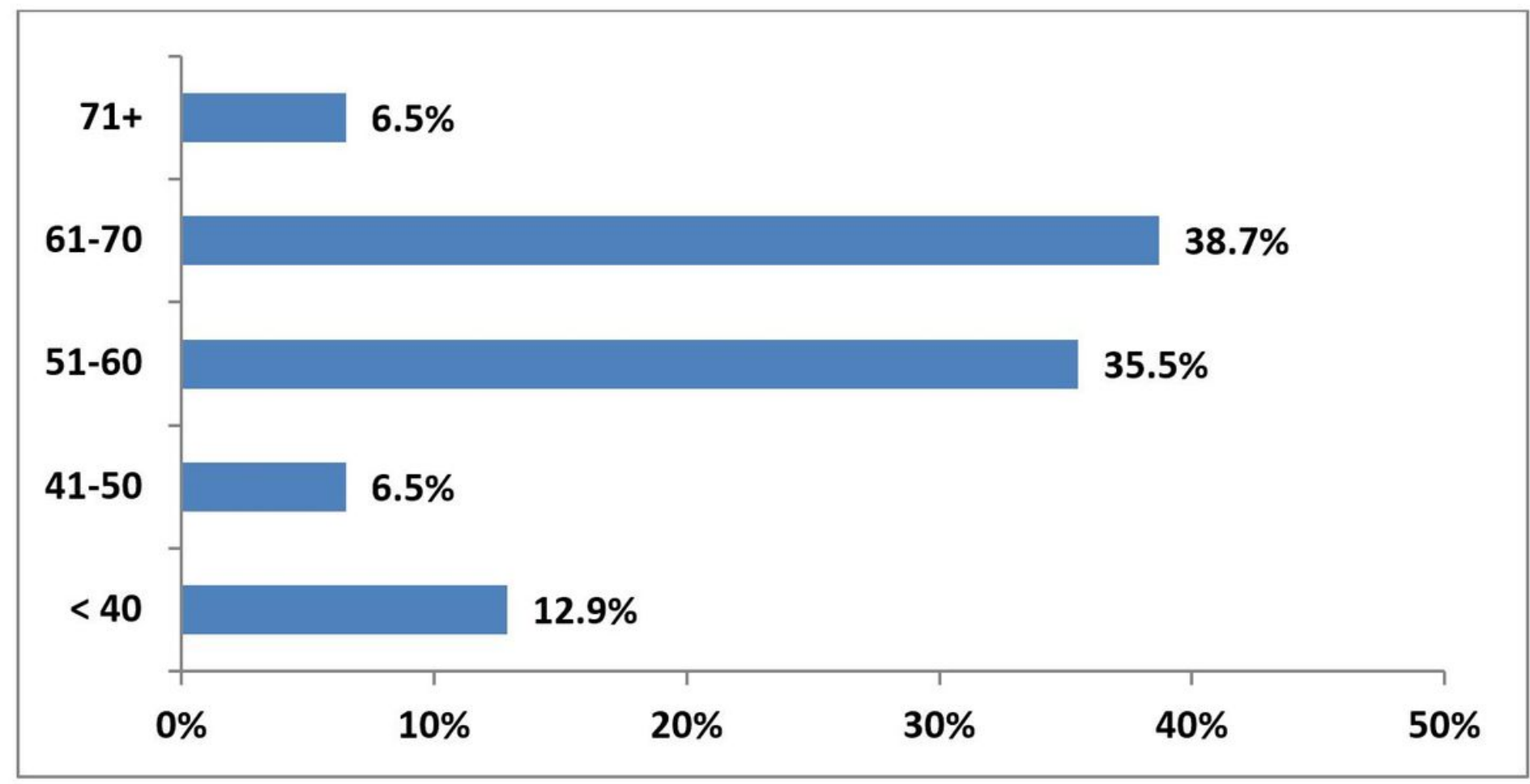

Figure 1

Distribution of patient's age group

\section{COMPLICATIONS}

$\longrightarrow$ Anastomotic Leak $\longrightarrow \mathrm{PPH} \longrightarrow \mathrm{POPF}$

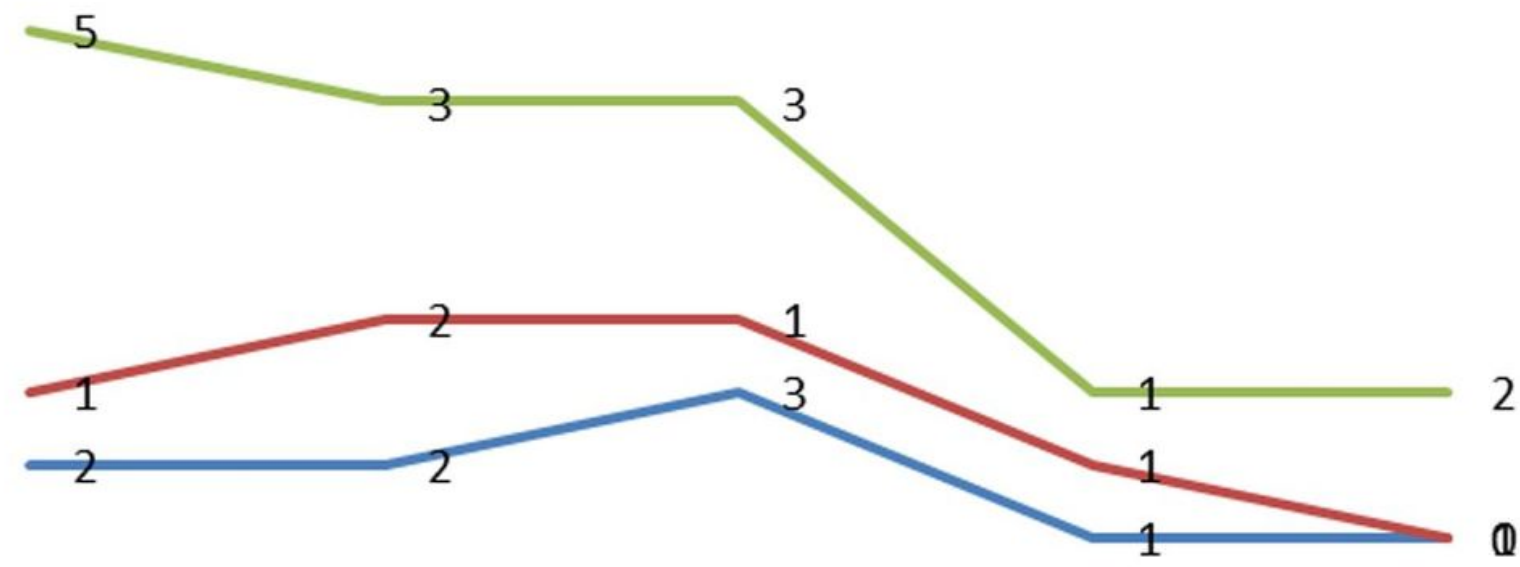

2015

2016

2017

2018

2019 
Figure 2

Year-wise trend of postoperative complications

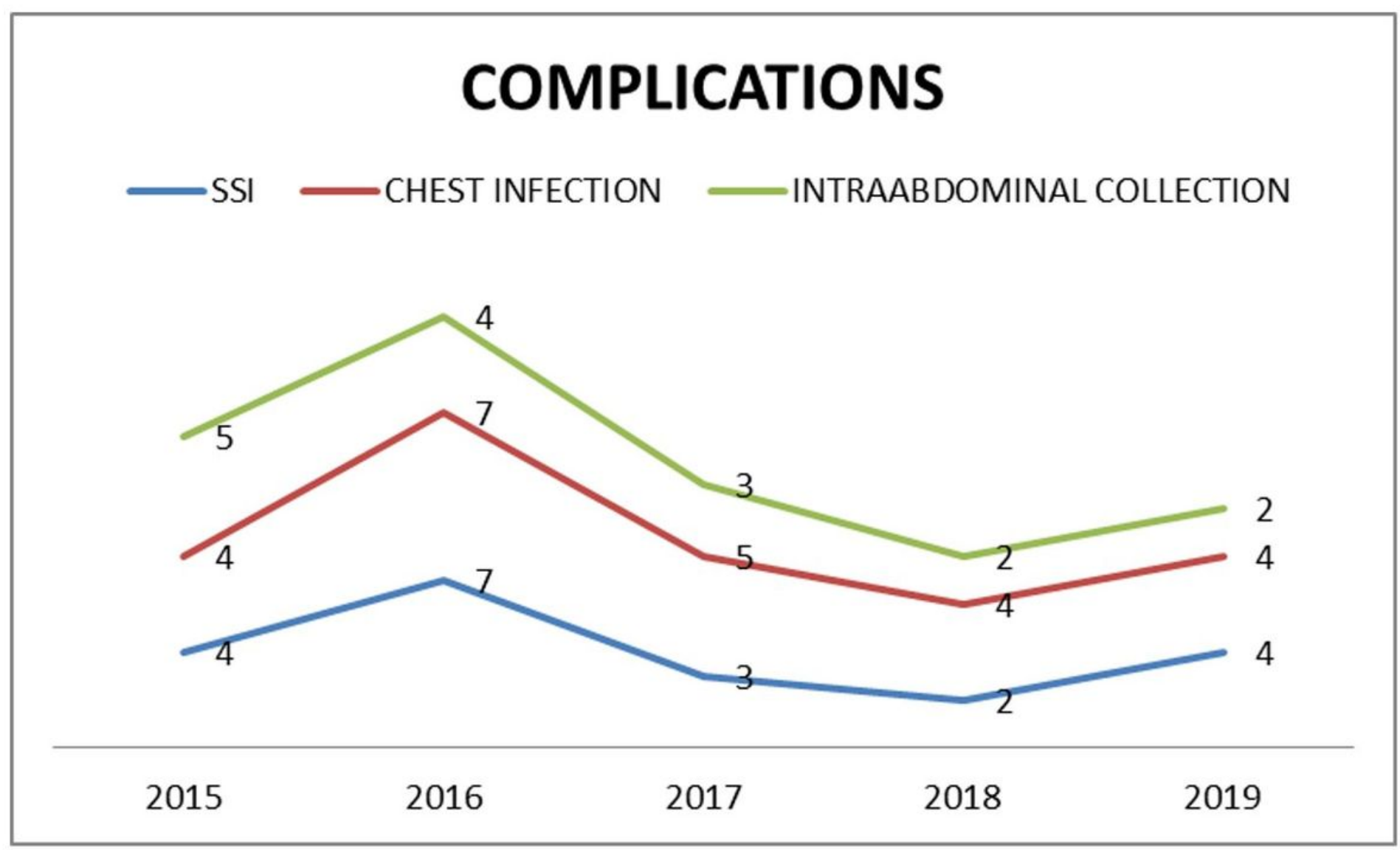

Figure 3

Year-wise trend of infective complication 


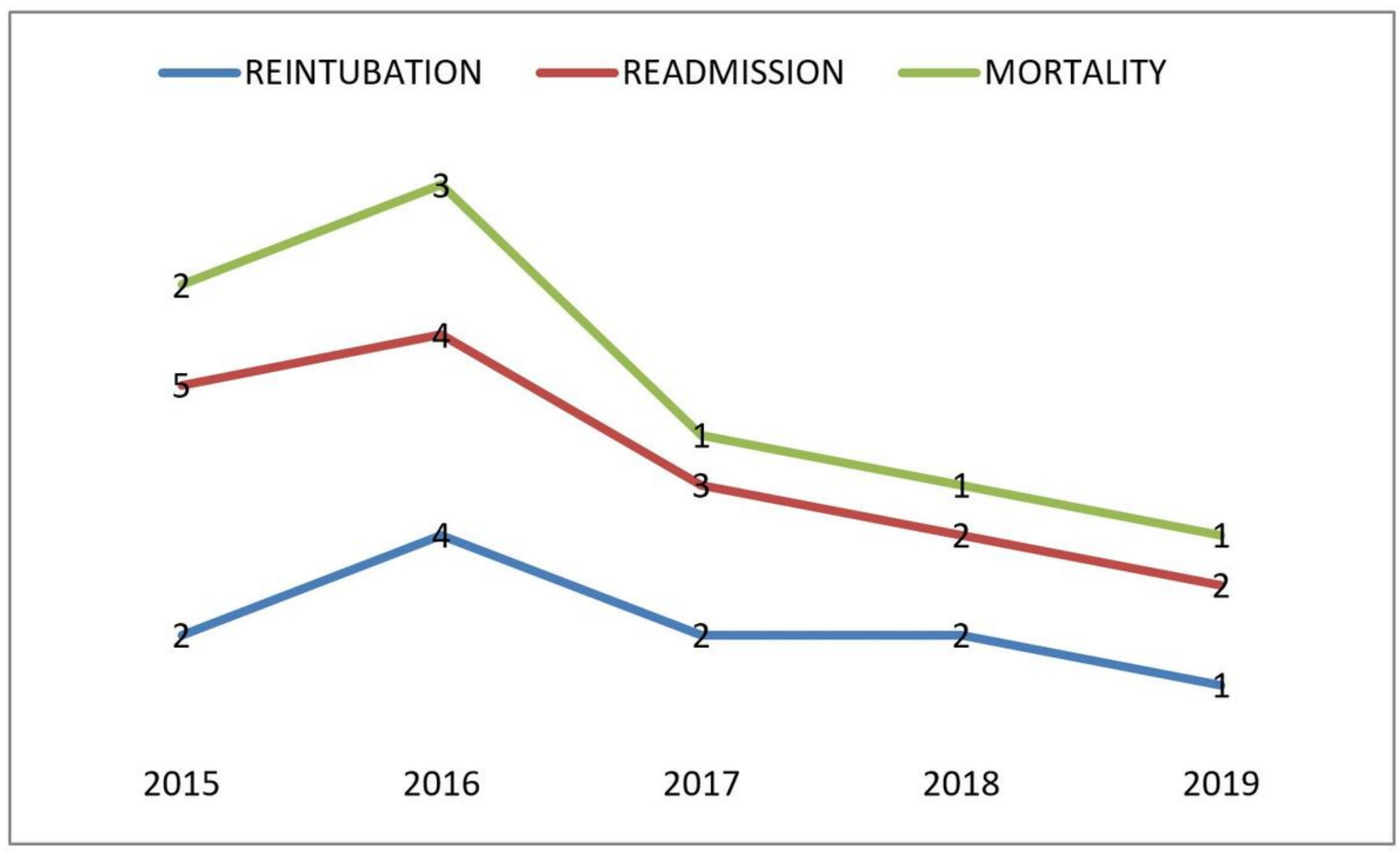

Figure 4

Trend of postoperative mortality and readmission 